\title{
1 SEX DIFFERENCES IN INDIVIDUAL FORAGING SITE FIDELITY OF
}

3 Lisa A. Sztukowski ${ }^{1}$, Peter A. Cotton ${ }^{1}$, Henri Weimerskirch ${ }^{2}$, David R. Thompson ${ }^{3}$, 4 Leigh G. Torres ${ }^{4}$, Paul M. Sagar ${ }^{5}$, Antony M. Knights ${ }^{1}$, Annette L. Fayet $^{6}$, Stephen C. $5 \quad$ Votier $^{7}$

6

$7 \quad{ }^{1}$ Marine Biology \& Ecology Research Centre, University of Plymouth, Plymouth, UK

$8{ }^{2}$ Centre d'Etudes Biologiques de Chizé, The National Center for Scientific Research, Chizé,

9 France

$10{ }^{3}$ National Institute of Water and Atmospheric Research Ltd., Wellington, New Zealand

$11{ }^{4}$ Department of Fisheries and Wildlife, Oregon State University, Newport, Oregon, USA

$12{ }^{5}$ National Institute of Water and Atmospheric Research Ltd., Christchurch, New Zealand

$13{ }^{6}$ Department of Zoology, University of Oxford, Oxford OX2 6GG, UK

$14{ }^{7}$ Environment and Sustainability Institute, University of Exeter, Cornwall Campus, Penryn,

15 Cornwall, UK

16

17 Lisa A. Sztukowski ${ }^{1}$ sztewy@gmail.com 
20 Inter-individual variation in behavioural traits has important implications for evolutionary 21 and ecological processes. Site fidelity, where individuals consistently use the same foraging site, is common among marine predators. Sex differences in foraging are also well studied in marine vertebrates, but the extent to which consistent inter-individual differences in foraging vary between the sexes is poorly known. Here we quantify the effects of sex on individual foraging site fidelity (IFSF), both within and between years, in chick brooding Campbell albatross (Thalassarche impavida). Using bird-borne Global Positioning System loggers, we calculated route fidelity (nearest neighbour distance), repeatability of site fidelity (terminal latitude and longitude), and foraging effort (total distance travelled and trip duration) during two to ten repeat trips. Overall, Campbell albatrosses showed a high degree of site fidelity.

30 Birds travelled to similar sites not only within the same year, but also between two consecutive years, suggesting that the within-year consistency is not simply in response to short-term patches of food. Moreover, within the same year there were differences in terms of IFSF between the sexes. Females that foraged closer to the colony in neritic and shelf waters were more likely to follow similar routes on repeated foraging trips and were more consistent in their foraging effort than males. Males that foraged further offshore in pelagic waters had more repeatable foraging longitudes than females. Our study provides further evidence of the importance of IFSF among marine vertebrates. However, it also reveals that the strength of such specialisations may vary with sex.

40 Key-words: route fidelity, foraging effort, GPS tracking, repeatability, sex effects 
Inter-individual trait variation has important implications for conservation, ecology and evolution (Bolnick et al. 2003, Araújo et al. 2011). For example, consistent individual variation in foraging behaviour, or foraging specialisation, can impact upon predator-prey interactions, parasitism risk, population and community dynamics, and lead to disruptive selection and evolutionary divergence (Darimont et al. 2007, Johnson et al. 2009, Duffy et al. 2010).

Individual foraging specialisation is common among a wide range of marine taxa including birds, fish, and mammals (reviews: Bolnick et al. 2003, Araújo et al. 2011, Ceia \& Ramos 2015). In marine species, individuals specialise in terms of their diet (Newsome et al. 2009, Tinker et al. 2012), searching behaviour (Woo et al. 2008, Torres \& Read 2009, Baylis et al. 2012, Patrick et al. 2014), isotopic niche (Bearhop et al. 2006, Jaeger et al. 2009, Votier et al. 2010) and, in particular, foraging location (Woo et al. 2008, Torres \& Read 2009, Baylis et al. 2012, Wakefield et al. 2015). Individual foraging site fidelity (IFSF), where an individual consistently uses only a small part of the population-level foraging range (Wakefield et al. 2015), is a particular form of individual specialisation that may arise as a consequence of predictable oceanographic conditions that generate foraging areas consistent in time and space (Weimerskirch 2007). However, variation in environmental conditions and different constraints such as those imposed by reproductive duties may influence the degree of site fidelity (Weimerskirch 2007, Patrick \& Weimerskirch 2017). Here we test for sex differences in IFSF in a marine predator engaged in central-place foraging, the Campbell albatross (Thalassarche impavida). Sex differences in foraging behaviour are well studied in marine vertebrates, including many seabirds (e.g. brown boobies Sula leucogaster, Miller et al. 2017; blackbrowed albatrosses Thalassarche melanophris, Huin 2002; northern gannets Morus bassanus, 

al. 2012; Cory's shearwaters Calonectris borealis, Paiva et al. 2017; northern giant petrels Macronectes halli, González-Solís et al. 2000). The mechanisms thought to influence sexual segregation include divergent parental roles or nutritional requirements, niche partitioning, competition, and social dominance (Weimerskirch et al. 2009). However, the extent to which IFSF varies between the sexes is not well known. One of the few study systems that have tested for sex differences in foraging individuality, in chick brooding black-browed albatrosses, found that females were more generalist than males (Patrick \& Weimerskirch 2014), although males showed stronger habitat fidelity than females (Patrick \& Weimerskirch 2017).

Here we studied IFSF in a large pelagic predator, the Campbell albatross, when restricted to foraging from a central place during the breeding season. The Campbell albatross is endemic to Campbell Island, New Zealand (52'32'24"S $\left.169^{\circ} 8^{\prime} 42^{\prime \prime} \mathrm{E}\right)$ and travels widely at sea to forage in waters off southern Australia, the Tasman Sea, and the southern Pacific Ocean (Waugh, Sagar, et al. 1999, Sztukowski 2016, Sztukowski et al. 2017). During chick brooding, Campbell albatross demonstrated sex differences in their distance travelled while foraging and also in habitat use (Sztukowski 2016). Such variation may influence IFSF between the sexes. Understanding the extent of IFSF may also be important in terms of conservation. The Campbell albatross population declined from 31,300 pairs in the 1940s to 21,648 pairs in 2012 (Waugh, Weimerskirch, et al. 1999, Sagar 2014); this, in addition to its restricted breeding range, habitat degradation, and the threat of fisheries bycatch led to

87 Campbell albatross being listed as vulnerable (BirdLife International 2012). Reversing these population trends and improving the future prospects of this species requires a more detailed understanding of their spatial ecology, including the degree of IFSF. 

brooding period, with the aim of studying IFSF in Campbell albatrosses. We first quantified the extent to which Campbell albatrosses demonstrate IFSF during repeated foraging trips within the same breeding season, specifically in terms of foraging location (distal point of trips), route fidelity (using nearest neighbour distance), and foraging effort (distances travelled and duration). As well as tracking repeat trips by the same individual within the same year, we also tracked some birds across two years to test for long-term IFSF. This will enable us to determine whether site fidelity occurs in response to short-term availability of prey patches, or is instead a longer-term foraging strategy. Finally, we compared the degree of IFSF between the sexes.

\section{METHODS}

\section{Instrumentation and tracking}

Chick brooding Campbell albatrosses were temporarily captured and tagged during the breeding seasons of November and December 2011/2012 and 2012/2013 (hereafter referred to as 2011 and 2012, respectively). Chicks hatched from late November through to mid-December (peak hatch during 2011 and 2012: 6-7 December, $\mathrm{n}=81$ nests). Modified GPS loggers (GT-600 i-gotU, Mobile Action Technology, Taiwan) were attached to the central back feathers of adult albatrosses using Tesa $\odot$ tape. Modification involved removing the external plastic housing of each logger then applying heat shrink tubing (FiniShrink, UK)

109 to waterproof each unit. The mass of each GPS unit was $\sim 33 \mathrm{~g}(\sim 1.1 \%$ of body mass $)$ and

110 programmed to record its location every ten minutes (referred to as a 'point' hereafter). We

111 studied at-sea foraging behaviour during early to mid-chick rearing; birds were re-captured

112 on the nest to remove the tag and retrieve the data following two or more complete foraging 
113 trips determined from nest attendance surveys, generally at the end of the chick brooding 114 stage.

\section{Analysis of tracking data}

Foraging trips were reconstructed using the GPS data, from which we calculated three

117 indices for complete foraging trips: (i) foraging route fidelity, (ii) foraging site fidelity, and

118 (iii) foraging effort (details below). All analyses were restricted to individuals with two or

119 more foraging trips; in most instances, our data represent all foraging trips taken by an 120 individual during the chick brooding stage. The degree of IFSF was calculated from 2 to 10 121 trips.

\section{$122 \quad$ Foraging route fidelity}

123 We calculated individual route fidelity using Nearest Neighbour Distance (NND, in

$124 \mathrm{~km})$. This technique quantifies the spatial similarity between a focal trip and a comparison

125 trip by calculating the distance from each location along a track to its nearest neighbour on

126 the comparison track (Biro et al. 2007). The NND calculated between two trips decreases

127 with the spatial similarity between the focal and comparison tracks. NND was calculated for 128 all possible pairs of trips (within individual trips, i.e. a measure of individual route fidelity, and among-individual trips, i.e. a measure of inter-individual variability). Locations $<2 \mathrm{~km}$ from the colony were removed to exclude non-foraging rafting behaviour near the colony.

We used linear mixed-effects models (LMM) to assess whether albatrosses showed route fidelity, by comparing within-individual NND to among-individual NND, first across all years (for the ten birds tracked in both years) and then within each year. To test for longterm IFSF, we first tested whether individuals followed more similar routes within the same year than in different years. Next, we tested for potential sex differences in route fidelity, by

136 comparing within-individual NND between males and females. All models included pair as a 
137 random effects and the difference in trip length between each pair of trips as a covariate. In 138 models testing data from multiple years, year was also included as a fixed effect. We

139 compared each model with the null (intercept only) model based upon likelihood-ratio tests

140 (LRT). NND was square root or log transformed to obtain normality.

\section{$141 \quad$ Foraging site fidelity}

142 To measure foraging site fidelity, we first estimated the terminal latitude and terminal

143 longitude (both in decimal degrees; DD) of each foraging trip. Terminal latitude and 144 longitude were defined as the location at the furthest point from the colony as calculated as a 145 straight-line distance. Based on sea-surface temperature (SST) and landing data, Campbell 146 albatrosses do not foraging actively while commuting to foraging zones (Weimerskirch \&

147 Guionnet 2002). We assumed the primary foraging zone was located at the furthest point

148 from the colony, but also qualify route fidelity (see above). We then compared the similarity 149 of these values between repeat distal locations based on repeatability $(R$, i.e. the proportion of 150 variance in a character that occurs among rather than within individuals or intra-class 151 coefficient; Lessells \& Boag 1987) for each sex and year. We used a LMM with restricted maximum likelihood (REML) and included individual as a random factor to account for multiple observations of the same bird. One thousand bootstrapping runs were performed to

154 estimate confidence intervals and standard errors (Nakagawa \& Schielzeth 2010). For the subset of individuals tracked in both years, we pooled the data from both years and included sex as a factor in LMM results in an adjusted repeatability $\left(R_{a d j}\right)$. All LMM analyses were undertaken using the "rptR" package in R (version 3.4.2; R Development Core Team 2017). Metrics for foraging behaviour were considered statistically repeatable if p-values were <

1590.05 and the degree of specialisation increased as repeatability index values tended towards 160 one. 
Foraging effort was calculated using two metrics: total distance travelled $(\mathrm{km})$ and

trip duration (hours), both calculated as the sum of the values from each point-to-point

164 location and then transformed using Box-Cox transformations to obtain normality. We

165 compared individual consistency of foraging effort between each sex and year by calculating

166 repeatability $(R)$. For the subset of individuals tracked in both years, we calculated an 167 adjusted repeatability.

\section{RESULTS}

\section{Foraging trip summary}

We obtained information on at-sea foraging behaviour from 63 birds $(n=237$ foraging trips): 12 females in 2011 ( $\mathrm{n}=42$ foraging trips), 26 females in $2012(\mathrm{n}=80$ foraging trips), 11 males in 2011 ( $\mathrm{n}=36$ foraging trips), and 24 males in $2012(\mathrm{n}=79$ foraging trips; Fig.1, 2, and Supplemental material). For ten individuals (6 females and 4 males), we obtained data in both 2011 and 2012 (Fig. 3). Total trip distances from the colony were, on average, significantly longer for males (mean \pm standard error: $1580.63 \pm 97.93 \mathrm{~km}$ ) than females $(1165.72 \pm 70.74 \mathrm{~km} ; \mathrm{t}=-3.43, \mathrm{df}=209.76, p<0.001)$ and trip durations were also greater for males $(56.53 \pm 3.03$ hours $)$ than females $(47.59 \pm 2.39$ hours; $t=-2.32$, $\mathrm{df}=$ 219.41, $p=0.02)$.

NNDs demonstrate that Campbell albatrosses showed individually consistent foraging

181 routes, with repeat trips being more similar within than between individuals (Fig 4) - this

182 result being consistent whether drawing comparisons across all years or within the same year 
183 (within 2011 LRT: $\chi_{1}^{2}=17.515, p<0.001$; within 2012 LRT: $\chi_{1}^{2}=25.002, p<0.001$; across

184 all years LRT: $\left.{ }_{1}^{2}=26.124, p<0.001\right)$. Moreover, route fidelity varied with sex - females had

185 significantly higher route fidelity compared with males (data pooled for all years; LRT: ${ }_{1}^{2}=$ $1864.5277, p=0.033$; Fig. 5). Trip length and year were both retained in the models, so these differences are not simply a function of the shorter foraging trips of females.

\section{Foraging site fidelity}

During 2-10 repeat trips, both males and females showed similar repeatability values

(Table 1). Repeatability of terminal latitude and longitude was significant for both sexes and within years, with the exception of females in 2011. Foraging site fidelity was generally higher in 2012 than 2011, with the highest repeatability estimates for male terminal longitude in 2012 (Table 1). For the ten individual with data from both years $(n=59$ foraging trips), repeatability of terminal longitude was significant $\left(R_{a d j}=0.376 \pm 0.155, p=0.007\right)$. Latitude was not significantly repeatable across years $\left(R_{a d j}=0.166 \pm 0.125, p=0.158\right)$.

\section{Foraging effort} foraging trips reveals that females tended to have higher within-individual variation than among-individual variation (Table 1). Females were significantly repeatable in total distance travelled and trip duration within both years, whereas males were significantly repeatable in total distance travelled in 2012 (Table 1). $0.149 \pm 0.116, p=0.109)$. 
During chick brooding, Campbell albatrosses tended to show consistent foraging routes, foraging sites, and foraging effort, suggesting a degree of IFSF. Moreover, for ten birds tracked in two breeding seasons, there was evidence of inter-annual route and site fidelity, indicating that the observed within-year patterns were not simply a response to short-

211 term profitable foraging opportunities (Table 1, Fig 1 - 4). Previous studies of albatrosses

212 have also shown variation with respect to IFSF; for instance, individual shy albatrosses

213 (Thalassarche cauta) consistently searched the same broad patch of ocean within a breeding stage, although individuals did not show fidelity to these patches across years (Hedd et al. 2001). Wandering albatrosses (Diomedea exulans) also showed short-term consistency in habitat use and trophic level; in the long-term, however, individuals were consistent in habitat use but not trophic niche (Ceia et al. 2012). Black-browed albatrosses showed similar patterns in terms of IFSF as shown in the present study, with strong within-year individuality that persisted, to an extent, across years (Patrick \& Weimerskirch 2017). Moreover, Patrick \& Weimerskirch (2017) showed that increased site fidelity was linked with higher reproductive success.

One of our key findings is that there were differences in the degree of IFSF between the sexes (Fig. 2, Supplemental material, Table 1). Males travelled further, had longer trip durations, and more consistent terminal longitude than females. Females were, however, more consistent in terms of their foraging route and effort (Fig 2, Supplemental material, Table 1). Previous research into how sex affects specialisation found diverse results. In the closely related black-browed albatross breeding on Kerguelen, males showed more consistent foraging locations than females (Patrick \& Weimerskirch 2014). The reasons for the difference from our study are unclear, but may be related to density dependence, since the degree of individual specialisation has been shown theoretically and experimentally to be 
231 linked with increased intraspecific competition (Svanbäck \& Bolnick 2005, 2007, Bolnick et

232 al. 2010). In our study, females Campbell albatross remained closer to the colony on the

233 Campbell Plateau, where competition is higher, and had a higher degree of route fidelity

234 compared with the more pelagic males. There may also be other factors at play. For instance,

235 studies of three species of inshore foraging pursuit diving shag and cormorant found that

236 females tend to be more consistent in foraging behaviour than males, which was explained by

237 a combination of morphological differences influencing resource accessibility, niche

238 partitioning, and prey choice (Kato et al. 2000, Cook et al. 2005, Ratcliffe et al. 2013). Size

239 may be important in our study species since male Campbell albatross are on average 7.2\%

240 heavier than females (Sztukowski 2016), which could affect foraging energetics and

241 behaviour. For example, wing length, wing area, mass, and associated wing loading were

242 consistent with the foraging distribution of male and female wandering albatrosses, which is

243 sexually dimorphic species; the morphological differences may be adaptive to exploiting

244 wind conditions associated with their associated habitats (Shaffer et al. 2001). Niche

245 partitioning may also be present. Female Campbell albatrosses tend to forage on the

246 Campbell Plateau were individuals fed predominantly on fish, whereas birds foraging in more

247 oceanic waters and around the polar front, where males tended to forage, feed mostly on

248 squid (NIWA 1999). However, while size may influence sex-specific foraging specialisation

249 and niche partitioning, specialisation may be linked to competition through size dimorphism,

250 reproductive role, or competitive exclusion (Phillips et al. 2004, Catry et al. 2006, Phillips et

251 al. 2011). Thus, while the factors driving sexual variation in specialisation may be similar to

252 those factors associated with sexual segregation, which include competitive exclusion, or

253 niche specialization associated with breeding role or morphology (Peters et al. 1983, Petit et

254 al. 1990, Marra 2000, Shaffer et al. 2001, Phillips et al. 2004, 2011, Catry et al. 2006,

255 Weimerskirch et al. 2009), more research is required to elucidate the mechanisms. 

commute to consistent foraging locations suggesting that individuals use previous knowledge to inform foraging decisions (Votier et al. 2017). The birds tracked over two years also tended to show similar foraging site fidelity, routes and total distance travelled. Such longerterm consistency suggests that the within-year consistency is not simply in response to shortterm patches of food (e.g. a win-stay, lose-shift tactic; Wakefield et al. 2015). Longer-term site fidelity, like those found in our study, may provide energetic advantages over an individual's lifetime despite environmental variability (Bradshaw et al. 2004). Thus, foraging site fidelity, in conjunction with fine-scale location adjustments within areas associated with predictable resources, may confer consistent energy intake (Bradshaw et al. 2004, Patrick et al. 2014).

To conclude, our study shows that there was generally a high degree of IFSF among chick brooding Campbell albatrosses, and individual consistency in foraging sites persisted across two consecutive years. However females, which remained closer to the colony to 270 forage in neritic/shelf habitats, had a higher degree of route fidelity and more repeatable 271 foraging effort compared with males which tend to use pelagic waters. While the causes of these differences remain unclear, our research highlights the possibility that threats posed by fisheries bycatch are not uniformly distributed across individuals or sexes within the 274 population, due to differences in their overlap with fisheries and reliance on fisheries waste 275 (Ryan 1999, Nel et al. 2002, Votier et al. 2010, Bugoni et al. 2011, Torres et al. 2011, 276 Barbraud et al. 2013, Torres et al. 2013). Further work should explore how these changes in site fidelity vary across the breeding season, as well as quantifying the potential impact of such risks. 
We would like to thank the Campbell field crews, boat crews, and DOC personnel

who made data collection possible. Special thanks to Caitlin Kroeger for field assistance,

Cox, Emilie Hall, Clare Embling, Loriane Mendez, and Andy Foggo for thoughtful

discussions and draft comments. R coding assistance was provided by David Pinaud, Duncan

Golicher, Michael Kemp, Wouter Vansteelant, and instructors on the Animal Movement

Course 2012, 2013. This study was funded through a MARES Grant (FPA 2011-0016),

National Institute of Water and Atmospheric Research Ltd. (NIWA), the New Zealand

Department of Conservation and the New Zealand Ministry of Business, Innovation and

Employment. Maps were created using QGIS software (Ocean Basemap Sources: ETOPO1

dataset hosted on the NOAA server and processed using "marmap" in R (Amante \& Eakins 2009, Pante \& Bouhet 2015).

\section{REFERENCES}

Amante C, Eakins BW (2009) ETOPO1 1 arc-minute global relief model: procedures, data sources and analysis. National Geophysical Data Center, NOAA, Boulder Colorado.

Araújo MS, Bolnick DI, Layman CA (2011) The ecological causes of individual specialisation. Ecol Lett 14:948-958

Barbraud C, Tuck GN, Thomson R, Delord K, Weimerskirch H (2013) Fisheries bycatch as an inadvertent human-induced evolutionary mechanism. Plos One 8:e60353

Baylis AM, Page B, McKenzie J, Goldsworthy SD (2012) Individual foraging site fidelity in lactating New Zealand fur seals: continental shelf vs. oceanic habitats. Mar Mammal Sci 28:276-294

Bearhop S, Phillips RA, McGill R, Cherel Y, Dawson DA, Croxall JP, others (2006) Stable isotopes indicate sex-specific and long-term individual foraging specialisation in diving seabirds. Mar Ecol Prog Ser 311:157-164

BirdLife International (2012) Thalassarche impavida. The IUCN Red List of Threatened Species. Version 2014.2 
Biro D, Freeman R, Meade J, Roberts S, Guilford T (2007) Pigeons combine compass and landmark guidance in familiar route navigation. Proc Natl Acad Sci 104:7471-7476

Bolnick DI, Ingram T, Stutz WE, Snowberg LK, Lau OL, Paull JS (2010) Ecological release from interspecific competition leads to decoupled changes in population and individual niche width. Proc R Soc B Biol Sci 277:1789-1797

Bolnick DI, Svanbäck R, Fordyce JA, Yang LH, Davis JM, Hulsey CD, Forister ML (2003) The ecology of individuals: incidence and implications of individual specialization. Am Nat 161:1-28

Bradshaw CJ, Hindell MA, Sumner MD, Michael KJ (2004) Loyalty pays: potential life history consequences of fidelity to marine foraging regions by southern elephant seals. Anim Behav 68:1349-1360

Bugoni L, Griffiths K, Furness RW (2011) Sex-biased incidental mortality of albatrosses and petrels in longline fisheries: differential distributions at sea or differential access to baits mediated by sexual size dimorphism? J Ornithol 152:261-268

Catry P, Phillips RA, Croxall JP (2006) Sexual segregation in birds: patterns, processes and implications for conservation. Sex Segreg Vertebr Ecol Two Sexes:351-378

Catry P, Ruxton GD, Ratcliffe N, Hamer KC, Furness RW (1999) Short-lived repeatabilities in long-lived great skuas: implications for the study of individual quality. Oikos:473479

Ceia FR, Phillips RA, Ramos JA, Cherel Y, Vieira RP, Richard P, Xavier JC (2012) Shortand long-term consistency in the foraging niche of wandering albatrosses. Mar Biol

Ceia FR, Ramos JA (2015) Individual specialization in the foraging and feeding strategies of seabirds: a review. Mar Biol 162:1923-1938

Cleasby IR, Wakefield ED, Bodey TW, Davies RD, Patrick SC, Newton J, Votier SC, Bearhop S, Hamer KC (2015) Sexual segregation in a wide-ranging marine predator is a consequence of habitat selection. Mar Ecol Prog Ser 518:1-12

Cook TR, Cherel Y, Tremblay Y (2005) Foraging tactics of chick-rearing Crozet shags: individuals display repetitive activity and diving patterns over time. Polar Biol 29:562-569

González-Solís J, Croxall JP, Wood AG (2000) Sexual dimorphism and sexual segregation in foraging strategies of northern giant petrels, Macronectes halli, during incubation. Oikos 90:390-398

Haury LR, McGowan JA, Wiebe PH (1978) Patterns and processes in the time-space scales of plankton distributions. In: Spatial pattern in plankton communities. p 277-327

Hedd A, Gales R, Brothers N (2001) Foraging strategies of shy albatross Thalassarche cauta breeding at Albatross Island, Tasmania, Australia. Mar Ecol Prog Ser 224:267-282 
Huin N (2002) Foraging distribution of the black-browed albatross, Thalassarche melanophris, breeding in the Falkland Islands. Aquat Conserv Mar Freshw Ecosyst 12:89-99

Hunt Jr GL, Schneider DC, others (1987) Scale-dependent processes in the physical and biological environment of marine birds. In: Seabirds: feeding ecology and role in marine ecosystems. p 7-41

Irons DB (1998) Foraging area fidelity of individual seabirds in relation to tidal cycles and flock feeding. Ecology 79:647-655

Jaeger A, Blanchard P, Richard P, Cherel Y (2009) Using carbon and nitrogen isotopic values of body feathers to infer inter- and intra-individual variations of seabird feeding ecology during moult. Mar Biol 156:1233-1240

Kamil AC (1983) Optimal foraging theory and the psychology of learning. Am Zool 23:291302

Kato A, Watanuki Y, Nishiumi I, Kuroki M, Shaughnessy P, Naito Y (2000) Variation in foraging and parental behavior of king cormorants. The Auk 117:718-730

Lessells CM, Boag PT (1987) Unrepeatable repeatabilities: a common mistake. The Auk:116-121

Levine M (1959) A model of hypothesis behavior in discrimination learning set. Psychol Rev $66: 353$

Miller MG, Silva FR, Machovsky-Capuska GE, Congdon BC (2017) Sexual segregation in tropical seabirds: drivers of sex-specific foraging in the brown booby Sula leucogaster. J Ornithol:1-13

Nakagawa S, Schielzeth H (2010) Repeatability for Gaussian and non-Gaussian data: a practical guide for biologists. Biol Rev 85:935-956

Nel D, Ryan PG, Nel JL, Klages NT, Wilson RP, Robertson G, Tuck GN, others (2002) Foraging interactions between wandering albatrosses Diomedea exulans breeding on Marion Island and long-line fisheries in the southern Indian Ocean. Ibis 144:E141E154

Newsome SD, Tinker MT, Monson DH, Oftedal OT, Ralls K, Staedler MM, Fogel ML, Estes JA (2009) Using stable isotopes to investigate individual diet specialization in California sea otters (Enhydra lutris nereis). Ecology 90:961-974

NIWA P (1999) Exploitation of the marine environment by two sympatric albatrosses in the Pacific Southern Ocean. Mar Ecol Prog Ser 117:243-254

Paiva VH, Pereira J, Ceia FR, Ramos JA (2017) Environmentally driven sexual segregation in a marine top predator. Sci Rep 7

Pante E, Bouhet BS (2015) Making and using bathymetric maps in R with marmap. 
Patrick SC, Bearhop S, Grémillet D, Lescroël A, Grecian WJ, Bodey TW, Hamer KC, Wakefield E, Le Nuz M, Votier SC (2014) Individual differences in searching behaviour and spatial foraging consistency in a central place marine predator. Oikos $123: 33-40$

Patrick SC, Weimerskirch H (2014) Consistency pays: sex differences and fitness consequences of behavioural specialization in a wide-ranging seabird. Biol Lett 10:20140630

Patrick SC, Weimerskirch H (2017) Reproductive success is driven by local site fidelity despite stronger specialisation by individuals for large-scale habitat preference. J Anim Ecol 86:674-682

Phillips RA, McGill RAR, Dawson DA, Bearhop S (2011) Sexual segregation in distribution, diet and trophic level of seabirds: insights from stable isotope analysis. Mar Biol 158:2199-2208

Phillips RA, Silk JRD, Phalan B, Catry P, Croxall JP (2004) Seasonal sexual segregation in two Thalassarche albatross species: competitive exclusion, reproductive role specialization or foraging niche divergence? Proc R Soc B Biol Sci 271:1283-1291

Ratcliffe N, Takahashi A, O'Sullivan C, Adlard S, Trathan PN, Harris MP, Wanless S (2013) The roles of sex, mass and individual specialisation in partitioning foraging-depth niches of a pursuit-diving predator. PloS One 8:e79107

Ryan PG (1999) Consistent male-biased seabird mortality in the Patagonian toothfish longline fishery. The Auk 116:851-854

Sagar PM (2014) Population estimates and trends of Campbell and grey-headed albatrosses at Campbell Island. NIWA

Shaffer SA, Weimerskirch H, Costa DP (2001) Functional significance of sexual dimorphism in wandering albatrosses, Diomedea exulans. Funct Ecol 15:203-210

Stauss C, Bearhop S, Bodey TW, Garthe S, Gunn C, Grecian WJ, Inger R, Knight ME, Newton J, Patrick SC (2012) Sex-specific foraging behaviour in northern gannets Morus bassanus: incidence and implications. Mar Ecol Prog Ser 457:151-162

Svanbäck R, Bolnick DI (2005) Intraspecific competition affects the strength of individual specialization: an optimal diet theory method. Evol Ecol Res 7:993-1012

Svanbäck R, Bolnick DI (2007) Intraspecific competition drives increased resource use diversity within a natural population. Proc R Soc B Biol Sci 274:839-844

Sztukowski LA (2016) Foraging ecology of the Campbell albatross: individual specialisation and fishery interactions. PhD dissertation, Plymouth University and Université Pierre et Marie Curie, Plymouth, UK

Sztukowski LA, Van Toor ML, Weimerskirch H, Thompson DR, Torres LG, Sagar PM, Cotton PA, Votier SC (2017) Tracking reveals limited interactions between Campbell albatross and fisheries during the breeding season. J Ornithol 158:725-735 
Tinker TM, Guimarães PR, Novak M, Marquitti FMD, Bodkin JL, Staedler M, Bentall G, Estes JA (2012) Structure and mechanism of diet specialisation: testing models of individual variation in resource use with sea otters. Ecol Lett 15:475-483

Torres LG, Read AJ (2009) Where to catch a fish? The influence of foraging tactics on the ecology of bottlenose dolphins (Tursiops truncatus) in Florida Bay, Florida. Mar Mammal Sci 25:797-815

Torres LG, Sagar PM, Thompson DR, Phillips RA (2013) Scaling down the analysis of seabird-fishery interactions. Mar Ecol Prog Ser 473:275-289

Torres L, Thompson D, Bearhop S, Votier S, Taylor G, Sagar P, Robertson B (2011) Whitecapped albatrosses alter fine-scale foraging behavior patterns when associated with fishing vessels. Mar Ecol Prog Ser 428:289-301

Votier SC, Fayet AL, Bearhop S, Bodey TW, Clark BL, Grecian J, Guilford T, Hamer KC, Jeglinski JW, Morgan G (2017) Effects of age and reproductive status on individual foraging site fidelity in a long-lived marine predator. In: Proc. R. Soc. B. The Royal Society, p 20171068

Votier SC, Grecian WJ, Patrick S, Newton J (2010) Inter-colony movements, at-sea behaviour and foraging in an immature seabird: results from GPS-PPT tracking, radio-tracking and stable isotope analysis. Mar Biol 158:355-362

Wakefield ED, Cleasby IR, Bearhop S, Bodey TW, Davies RD, Miller PI, Newton J, Votier SC, Hamer KC (2015) Long-term individual foraging site fidelity-why some gannets don't change their spots. Ecology 96:3058-3074

Waugh SM, Sagar PM, Cossee RO (1999) New Zealand black-browed albatross Diomedea melanophrys impavida and grey-headed albatross D. chrysostoma banded at Campbell Island: Recoveries from the South Pacific Region. Emu 99:29-35

Waugh SM, Weimerskirch H, Moore PJ, Sagar PM (1999) Population dynamics of blackbrowed and grey-headed albatrosses Diomedea melanophrys and D. chrysostoma at Campbell Island, New Zealand, 1942-96. Ibis 141:216-225

Weimerskirch H (2007) Are seabirds foraging for unpredictable resources? Deep Sea Res Part II Top Stud Oceanogr 54:211-223

Weimerskirch H, Guionnet T (2002) Comparative activity pattern during foraging of four albatross species. Ibis 144:40-50

Weimerskirch H, Shaffer SA, Tremblay Y, Costa DP, Gadenne H, Kato A, Ropert-Coudert Y, Sato K, Aurioles D (2009) Species- and sex-specific differences in foraging behaviour and foraging zones in blue-footed and brown boobies in the Gulf of California. Mar Ecol Prog Ser 391:267-278

Wiley AE, Welch AJ, Ostrom PH, James HF, Stricker CA, Fleischer RC, Gandhi H, Adams J, Ainley DG, Duvall F (2012) Foraging segregation and genetic divergence between geographically proximate colonies of a highly mobile seabird. Oecologia 168:119130 
456

457

458

459

460

461
Woo KJ, Elliott KH, Davidson M, Gaston AJ, Davoren GK (2008) Individual specialization in diet by a generalist marine predator reflects specialization in foraging behaviour. $\mathbf{J}$ Anim Ecol 77:1082-1091 
462 Table 1: Repeatability ( $R \pm$ Standard Error, p-values in parentheses) of female (12 463 individuals in 2011, $\mathrm{n}=42$ foraging trips; 26 individuals in $2012, \mathrm{n}=80$ foraging trips) and 464 male (11 individuals in 2011, n=36 foraging trips; 24 individuals in 2012, $\mathrm{n}=79$ foraging 465 trips) Campbell albatross foraging site fidelity and foraging effort. Significant repeatability 466 estimates are highlighted in bold.

\section{Foraging effort}

Total distance $(\mathrm{km})$

2011

2012

Trip duration (hrs)

2011

2012

Foraging site fidelity

Terminal latitude (DD)

2011

2012

Terminal longitude (DD)

2011

2012
Female

$0.344 \pm 0.172(p=0.039)$

$0.340 \pm 0.126(p=0.003)$

$\mathbf{0 . 4 3 4} \pm \mathbf{0 . 1 6 7}(\boldsymbol{p}=\mathbf{0 . 0 1 6}) \quad 0.099 \pm 0.134(p=0.327)$

$0.322 \pm 0.127(p=0.003)$

Female

$0.295 \pm 0.172(p=0.115)$

$0.554 \pm 0.110(p<0.001)$

$0.356 \pm 0.173(p=0.095)$

$0.538 \pm 0.114(p<0.001)$
Male

$0.074 \pm 0.129(p=0.362)$

$0.215 \pm 0.121(p=0.039)$

$0.059 \pm 0.086(p=0.336)$

Male

$0.366 \pm 0.179(p=0.024)$

$0.394 \pm 0.122(p<0.001)$

$0.399 \pm 0.173(p=0.013)$

$0.603 \pm 0.107(p<0.001)$ 
468 Figure 1. Foraging trips taken by female (in red) and males (in yellow) Campbell albatrosses 469 in 2011 (panel 1) and 2012 (panel 2). The location of Campbell Island is indicated by the 470 white triangle.

471 Figure 2. Foraging trips taken by individual Campbell albatrosses. First column illustrates 472 the highest route fidelity (lowest NND) within each sex and year. Second column shows 473 foraging trips from the median individual from each sex-year category when individuals were 474 ranked from lowest average NND to highest average NND. Individual foraging trips in the 475 third columns demonstrate low levels of route fidelity (highest NND). Distal locations for 476 each foraging trip are indicated in green and the location of Campbell Island is highlighted by 477 the white triangle. All foraging trips are available in the supplemental materials which are 478 grouped by sex and year.

479 Figure 3. Foraging trips taken by individual Campbell albatrosses tracked in both 2011 (in 480 red) and 2012 (in yellow). Distal locations for each foraging trip are indicated in green and 481 the location of Campbell Island is highlighted by the white triangle. Panels are grouped by 482 sex.

483 Figure 4. Nearest-neighbour distance (NND \pm s.d. in $\mathrm{km}$ ) shows that individual route fidelity 484 across all years is greater within individuals than among individuals.

485 Figure 5. Nearest-neighbour distance (NND \pm s.d. in $\mathrm{km}$ ) shows that females tend to have 486 higher route fidelity than males. 

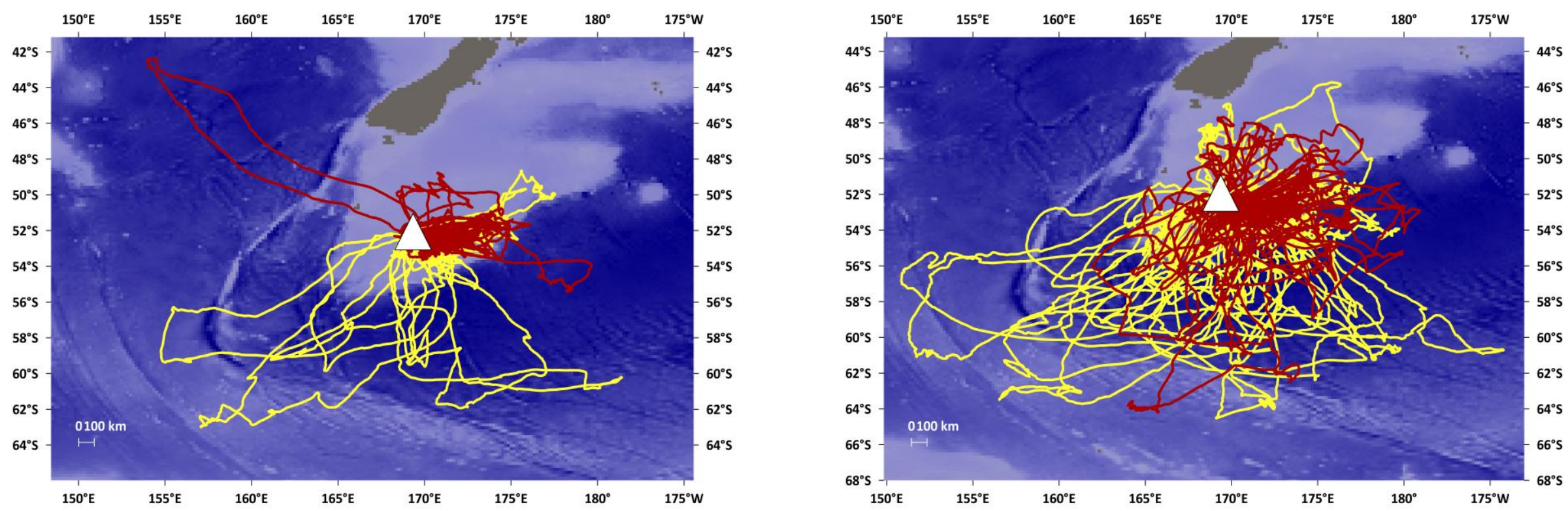

Figure 1 
Female 2011
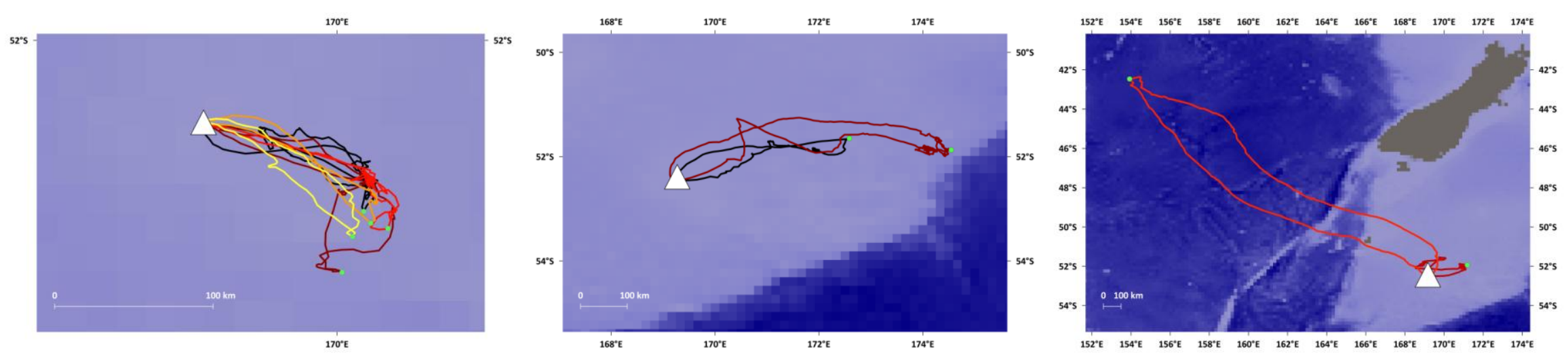

Male 2011
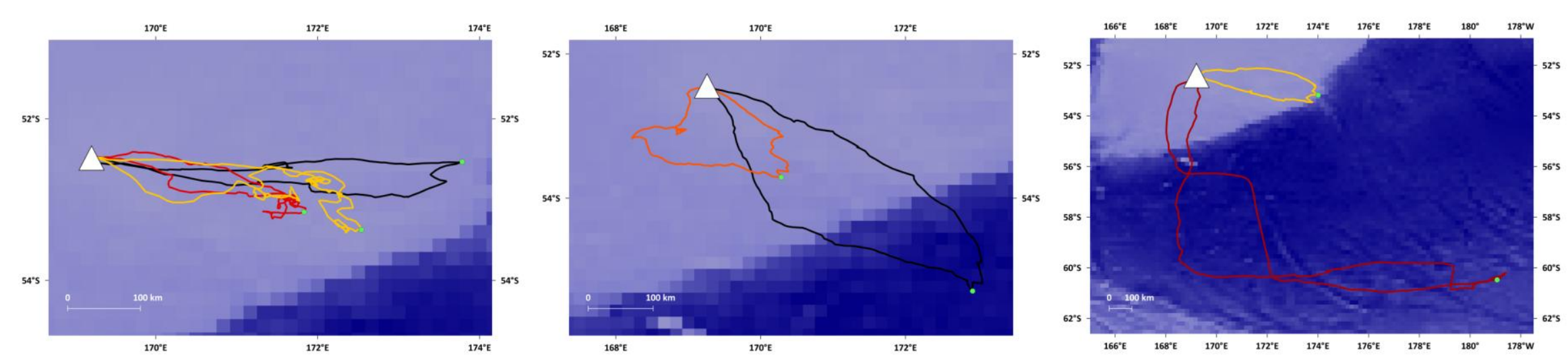

Figure 2 
Female 2012
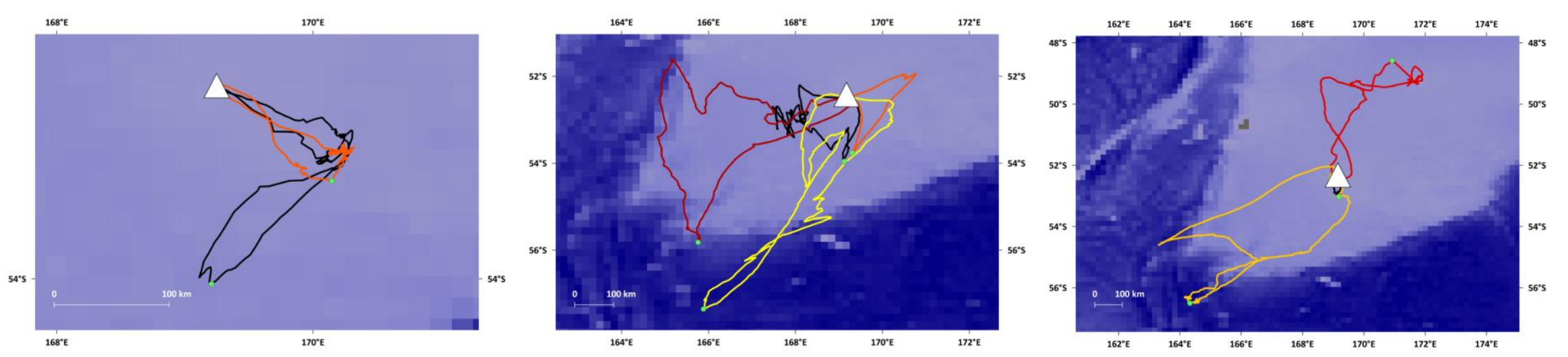

Male 2012
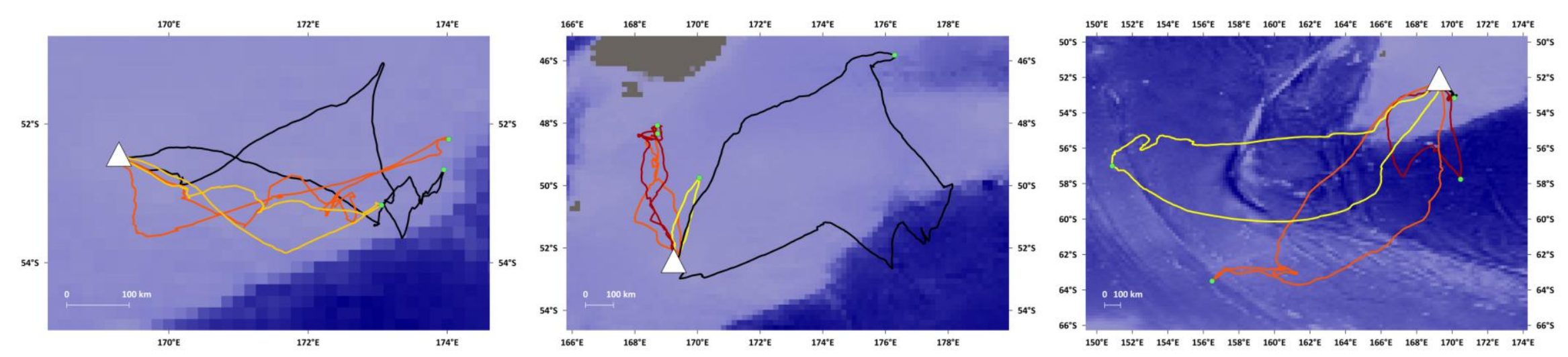

Figure 2 continued 
Female
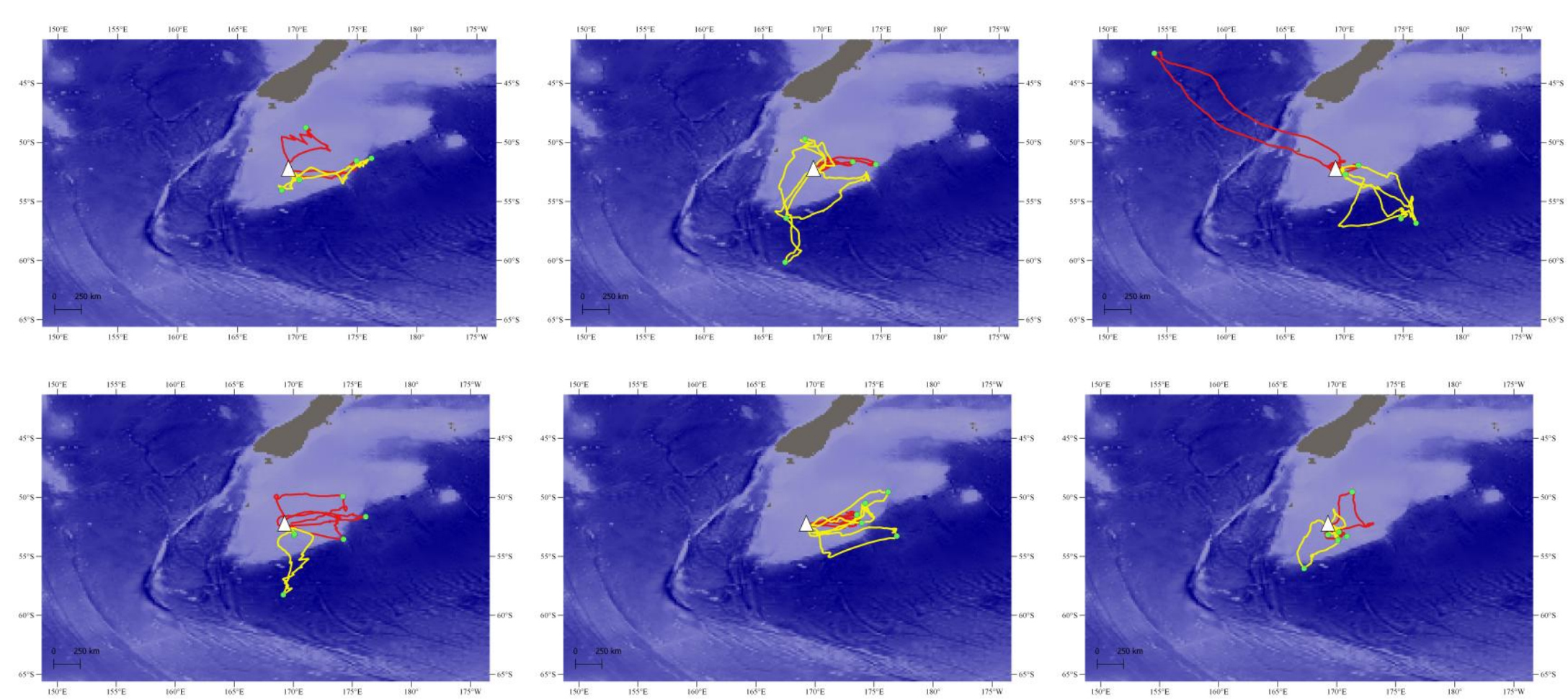

Figure 3 
Male
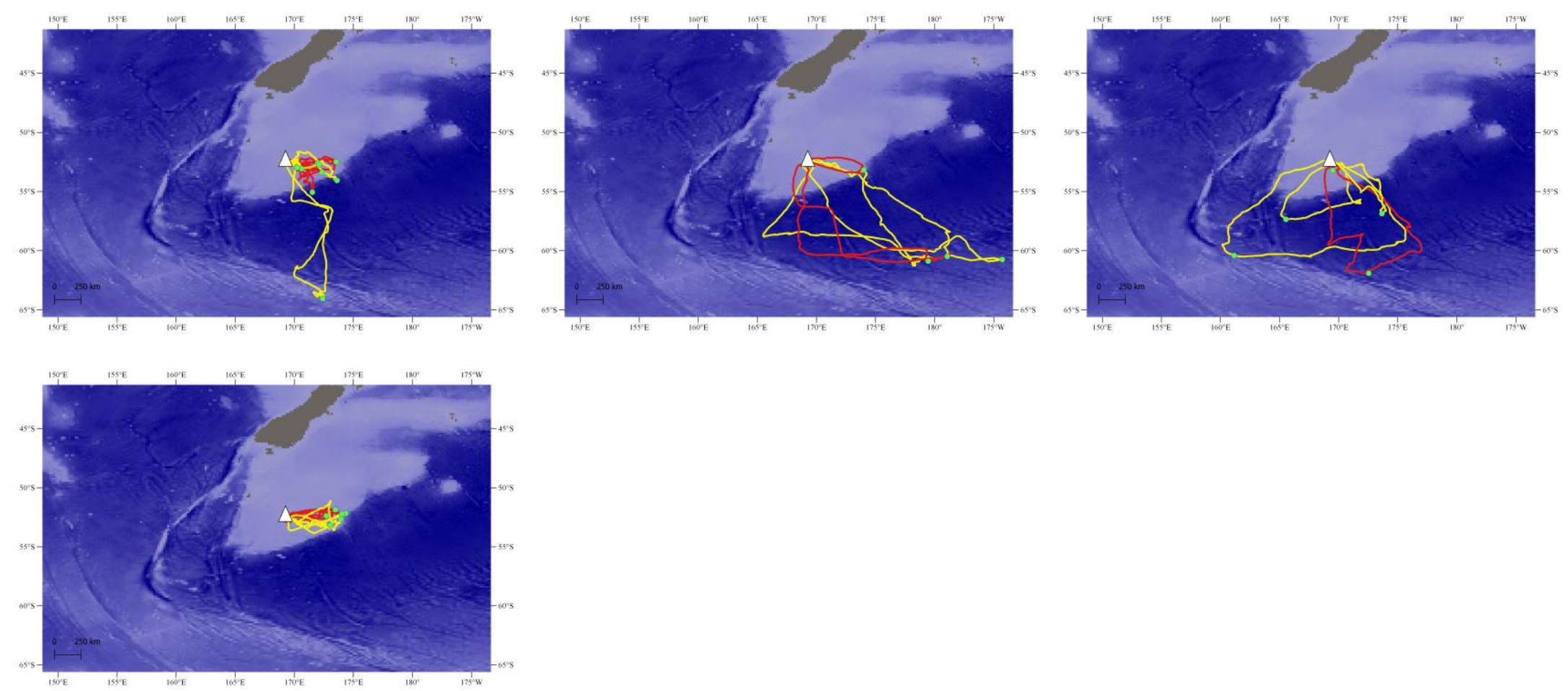

Figure 3 continued 

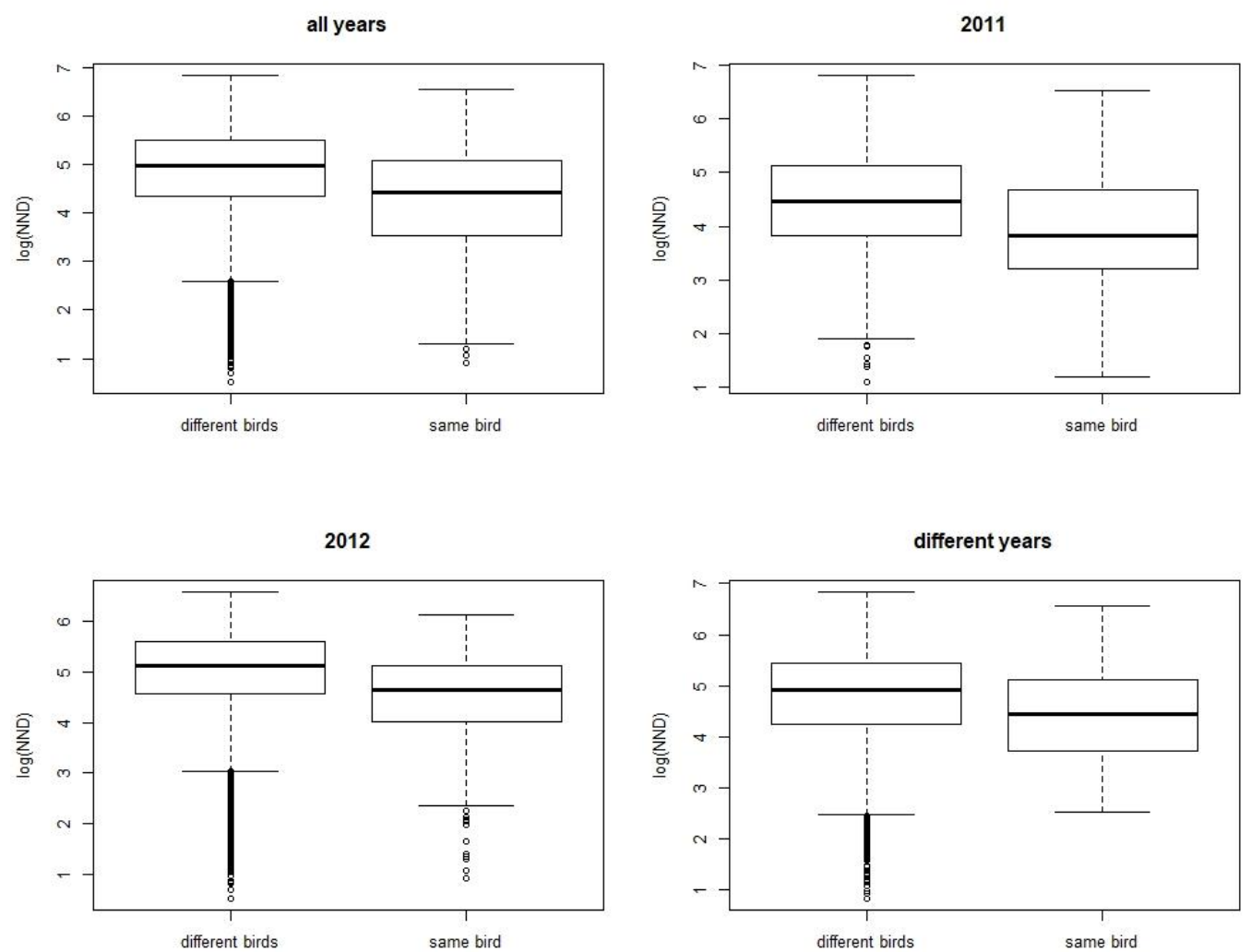

Figure 4

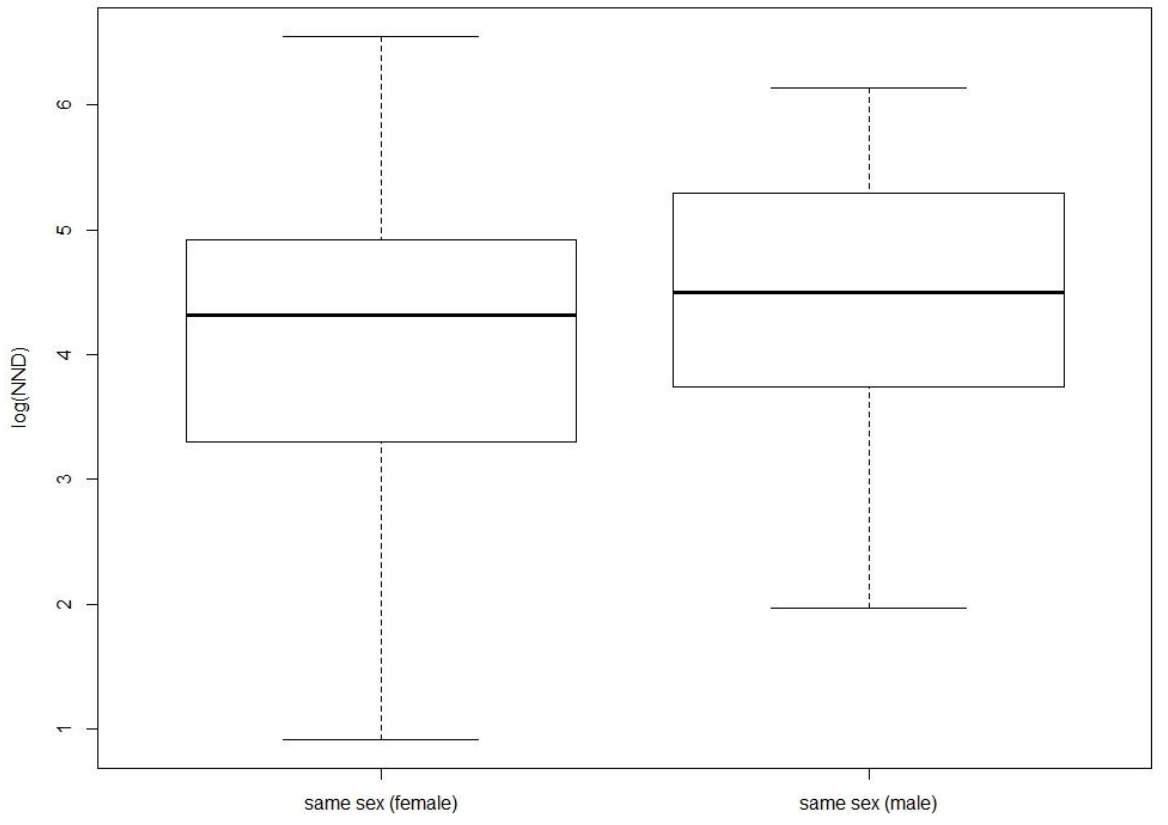

Figure 5 